\title{
Increasing fresh gas flows of oxygen in a circle absorber system for preoxygenation. Is it really efficacious?
}

\author{
Madhavi Sanjay Chaudhari', Piyush Bansal ${ }^{2, *}$, Birva Khara ${ }^{3}$ \\ ${ }^{1}$ Professor, ${ }^{2}$ Senior Resident, ${ }^{\mathbf{3}}$ Associate Professor, Dept. of Anaesthesiology, ${ }^{\mathbf{1}, 3}$ Pramukhswami Medical College and Shree \\ Krishna Hospital, Karamsad, Gujarat, ${ }^{2}$ Vardhman Mahavir Medical College \& Safdarjung Hospital, New Delhi, India
}

\author{
*Corresponding Author: Piyush Bansal \\ Email: piyushbnsal@gmail.com
}

Received: $6^{\text {th }}$ February, 2018

Accepted: $9^{\text {th }}$ August, 2018

\begin{abstract}
Introduction: Preoxygenation is a routine practice prior to induction of general anaesthesia. The fresh gas flow (FGF) of oxygen used is an important factor for an effective preoxygenation, and the end tidal oxygen fraction $\left(\mathrm{FeO}_{2}\right)$ is the most sensitive indicator for its adequacy. This study determines the ideal time for preoxygenation at different FGFs, and the effect of increasing the FGF on the time for preoxygenation.

Materials and Methods: Ninety patients of ASA grade I/II, aged 18-65yr, weighing $50-80 \mathrm{~kg}$ and scheduled for elective surgery under general anaesthesia were divided by a computer generated random allocation table into three study groups ( 30 each) Group 8, Group 10 and Group 12, according to the FGF used. A circle absorber system and a face mask were used for preoxygenation with one of the FGFs and tidal volume breathing technique. The values of $\mathrm{FeO}_{2}$ and blood peripheral oxygen saturation $\left(\mathrm{SpO}_{2}\right)$ were recorded at prefixed intervals. The primary outcome variable i.e., time (sec) required for achieving $\mathrm{FeO}_{2}$ of $\geq 90 \%$ was recorded. The secondary outcome variable i.e., the effect on the time to reach $\mathrm{FeO}_{2} \geq 90 \%$ with change in FGF was noted. All continuous variables across the 3 groups were compared by applying ANOVA test.

Results: All the groups showed statistically significant difference among each other for the time to reach $\mathrm{FeO}_{2} \geq 90 \%(\mathrm{P}=0.000)$. The Mean $( \pm \mathrm{SD})$ time taken to achieve $\mathrm{FeO}_{2} \geq 90 \%$ was, Group $8=284.07 \pm 36.92 \mathrm{sec}$, Group $10=199.87 \pm 20.71 \mathrm{sec}$, and Group $12=140.67 \pm 27.88 \mathrm{sec}$. The secondary outcome is that the Group 12 took the least time and Group 8 took the maximum time.

Conclusions: The time for preoxygenation ranges between 2 to 5 min depending on the FGF, and this time decrease with an increase in the FGF.
\end{abstract}

Keywords: Preoxygenation, Fresh gas flow, End tidal oxygen, Circle system, Tidal volume breathing.

\section{Introduction}

Preoxygenation is done routinely in all the patients prior to induction of general anaesthesia to provide a duration of apnea without desaturation (DAWD), ${ }^{1,2}$ i.e. peripheral oxygen saturation $\left(\mathrm{SpO}_{2}\right)>90 \%$, of $5-10$ minutes. This is necessary to avoid hypoxemia during the brief apnea interval produced immediately after the induction of anaesthesia and muscle relaxation, until the ventilation is restored. It is of utmost importance in cases of unanticipated or anticipated difficult airway, or in rapid sequence inductions..$^{1,3-8}$ Hypoxemia increases the risk of hemodynamic instability, cardiac arrhythmias, hypoxic brain injury and death. ${ }^{2,9,10}$ Preoxygenation is said to be maximally achieved when the alveolar, vascular and tissue compartments are all filled with oxygen $\left(\mathrm{O}_{2}\right)^{5,11}$ although the main reserve being the functional residual capacity (FRC) of the lungs. ${ }^{5}$ Preoxygenation is considered complete when the end tidal oxygen fraction $\left(\mathrm{FeO}_{2}\right)$ is $\geq 90 \%$ or end tidal nitrogen fraction $\left(\mathrm{FeN}_{2}\right)$ is $\leq 5 \%$. ${ }^{1,3,4}$

Previous studies on preoxygenation have used different breathing techniques, ${ }^{6,11,12,13}$ different breathing systems, ${ }^{8,14}$ different patient positions, different sets of patient groups (pregnant, ${ }^{15}$ obese, ${ }^{16}$ elderly ${ }^{17,18}$ as well as the importance of good face mask seal for preoxygenation. ${ }^{13,19,20}$ But, only few studies have observed the effect of different fresh gas flows (FGF) on time required for preoxygenation.

This study was undertaken to estimate the time required for adequate preoxygenation by using tidal volume breathing (TVB) technique on a circle absorber system, at different FGFs.

\section{Materials and Methods}

Following approval from the Human Research and Ethical Committee, 90 ASA grade I or II patients of age $18-65 \mathrm{yr}$, weighing $50-80 \mathrm{~kg}\left(\mathrm{BMI}<30 \mathrm{~kg} / \mathrm{m}^{2}\right)$, posted for elective surgery under general anaesthesia were enrolled in the study prospectively after explaining them about the study and technique, and taking written and informed consent. Patients with pregnancy, significant systemic pathology, thoracic injuries, difficult face mask seal and anemia were excluded from the study. All patients were divided into three groups (30 patients each), based on the different FGF delivered to the patients. A sample size of 30 per group was considered as it has enough power to find a significant difference according to the statistical thumb rule.

The circle absorber system of a single anaesthesia machine (Dragger Fabius Plus Dräger Medical AG \& Co. KG, Germany) was used for the study with a disposable corrugated breathing circuit and a $2 \mathrm{~L}$ reservoir bag. The circuit was primed by flushing with 
$100 \%$ oxygen till a $\mathrm{FiO}_{2}$ (fraction of inspiratory oxygen) of $95 \%$ was attained, before each procedure. After priming was complete, the dragger oxygen analyzer (galvanic cell) was switched over to the expiratory limb of the circle system, for recording $\mathrm{FeO}_{2}$ values. The analyzer was calibrated before each use. Patients were allowed to become familiar with face mask breathing before applying a tight seal with a clean black antistatic rubber face mask with pneumatic seal of appropriate size. The seal was made only tight enough so as not to cause any discomfort to the patient. The patients were preoxygenated in supine position, by asking the patients to breath normally i.e. TVB technique, at one of the desired FGF's- 8,10 or 12 $\mathrm{L} / \mathrm{min}$ on the anaesthesia machine, as allotted by the computer generated random assignment table. Standard monitoring was carried out throughout the procedure, after recording of baseline readings at room air breathing, which included electrocardiogram (ECG), $\mathrm{SpO}_{2}$, non invasive blood pressure (NIBP), respiratory rate and end tidal $\mathrm{CO}_{2}\left(\mathrm{EtCO}_{2}\right)$. The adequacy of face mask fitting was confirmed by the value of tidal volume generated as seen on the anaesthesia machine, and the wave form of the capnogram. $\mathrm{FeO}_{2}$ and $\mathrm{SpO}_{2}$ were recorded every $10 \mathrm{sec}$ for the first minute, every $20 \mathrm{sec}$ for the next $2 \mathrm{~min}$ i.e. till $3 \mathrm{~min}$, and then every $30 \mathrm{sec}$ after that. Readings were taken till a $\mathrm{FeO}_{2} \geq 90 \%$ value was achieved on the anaesthesia machine. The primary outcome measure which is time taken to achieve $\mathrm{FeO}_{2}$ $\geq 90 \%$ value was recorded using a stopwatch. The secondary outcome measure that is the effect on the time to reach $\mathrm{FeO}_{2} \geq 90 \%$ with change in FGF was noted.

The data were recorded on a Microsoft Excel sheet and summarized as the means and standard deviations
(Mean \pm SD). Statistical analysis was performed using STATA 14 software. All continuous variables across all the three groups were compared by applying Analysis of Variance (ANOVA). Where a significant $P$ value was found, further post hoc analysis was done by applying Tukey HSD (Honest Significant Difference) test. For comparison of gender, Chi Square test was applied. A 'P' value of $<0.05$ was considered as significant.

\section{Results}

A total of 90 patients were studied under three groups. The values of Mean $\pm \mathrm{SD}$ of the demographic variables (age, weight and height) and the gender distribution of all the three groups are summarized in Table 1. All the groups were found statistically comparable to each other as suggested by the $\mathrm{P}$ values. The mean time required to achieve $\mathrm{FeO}_{2} \geq 90 \%$ across all the three groups was $208.20 \pm 65.86 \mathrm{sec}$. The mean time taken by the patients in different groups Group $8=$ $284.07 \pm 36.92 \mathrm{sec}$, Group $10=199.87 \pm 20.71 \mathrm{sec}$, and Group $12=140.67 \pm 27.88 \mathrm{sec}$ (Table 2). All the three groups were found to be statistically different from each other for the time taken to reach $\mathrm{FeO}_{2}$ value $\geq 90 \%$. P value of 0.000 was obtained, which is statistically significant. The secondary outcome is that, the Group 12 took the least time and Group 8 took the maximum time.

The mean baseline $\mathrm{SpO}_{2}(\%)$ value in the three groups was as follows, Group 8- 99.63 \pm 0.68 , Group 10$99.53 \pm 0.67$, and Group 12- 99.7 \pm 0.65 . The $\mathrm{SpO}_{2}$ at $\mathrm{FeO}_{2} \geq 90 \%$ for all the patients across all three groups was recorded to be $100 \%$.

Table 1. Comparison of demographic variables between the groups

\begin{tabular}{|l|c|c|c|c|}
\hline & Group 8 & Group 10 & Group 12 & P value \\
\hline Age $(\mathrm{yr})$ & $34.33 \pm 11.44$ & $32.13 \pm 10.38$ & $29.37 \pm 9.09$ & 0.183 \\
\hline Weight $(\mathrm{kg})$ & $63.23 \pm 7.91$ & $62.60 \pm 7.71$ & $64.97 \pm 6.69$ & 0.448 \\
\hline Height $(\mathrm{cm})$ & $168.50 \pm 4.42$ & $163 \pm 30.94$ & $167 \pm 4.45$ & 0.505 \\
\hline Sex $(\mathrm{f} / \mathrm{m})$ & $11 / 19$ & $10 / 20$ & $13 / 17$ & 0.718 \\
\hline
\end{tabular}

Table 2. Mean time to reach $\mathrm{FeO}_{2} \geq 90 \%$ for the groups

\begin{tabular}{|l|c|c|c|c|}
\hline & Group 8 & Group 10 & Group 12 & P value \\
\hline Time for $\mathrm{FeO}_{2} \geq 90 \%(\mathrm{sec})$ & $284.07 \pm 36.92$ & $199.87 \pm 20.71$ & $140.67 \pm 27.88$ & 0.000 \\
\hline
\end{tabular}

\section{Discussion}

Preoxygenation increases the safety margin between the induction of anaesthesia and securing the airway. The purpose of preoxygenation is to replace the nitrogen in the lungs by oxygen and to increase the oxygen reserves of the body. Therefore, the term 'Denitrogenation' can be used interchangeably with the term 'Preoxygenation'. ${ }^{1,4}$ Since the 'cannot intubate, cannot ventilate' situation is unpredictable, preoxygenation should be carried out in all the patients planned for general anaesthesia, as a routine practice. ${ }^{1,4,11}$ For patients with limited oxygen reserves, e.g. obese, pregnant patients, anemia or in cases where manual ventilation is undesirable as in rapid sequence inductions for high risk of aspiration, critical illness, etc., preoxygenation should be mandatory. ${ }^{2-4,21}$ It has also been adopted as a crucial step by various guidelines for management of difficult airway, for all the patients before induction of general anaesthesia. ${ }^{22-24}$

The effectiveness of preoxygenation is assessed by its efficacy and efficiency. ${ }^{4}$ The indices measuring the 
efficacy are increase in fraction of alveolar $\mathrm{O}_{2}$, decrease in fraction of alveolar $\mathrm{N}_{2}$ and increase in arterial $\mathrm{O}_{2}$ tension, which are further affected by factors like $\mathrm{FiO}_{2}$, FGF, presence of leak, duration of breathing, anaesthesia system used and alveolar ventilation/FRC ratio. The efficiency is measured by decline in $\mathrm{SpO}_{2}$ during apnea which depends on factors like FRC, cardiac output, arterial $\mathrm{O}_{2}$ content, alveolar $\mathrm{O}_{2}$ tension, volume of $\mathrm{O}_{2}$ in lungs and $\mathrm{O}_{2}$ demand versus supply balance.

In our study the patients were brought unpremedicated to the operation theatre, as any pre procedure anxiolytic drug could have led to decreased respiratory efforts hampering the effective preoxygenation. They were thoroughly informed about the procedure and the face mask breathing for good compliance to avoid any leak. Leaks from the mask can reduce the $\mathrm{FiO}_{2}$ delivered and lead to submaximal preoxygenation. ${ }^{20} \mathrm{We}$ used a circle absorber system of an anaesthesia machine with a face mask in this study because it is the most commonly used system in our hospital setup and also it leads to less rebreathing of gases with high FGFs, which is beneficial for an effective preoxygenation., ${ }^{72,14}$ The capnograph was used to judge the adequacy of the face mask fit. Many new anaesthesia machines can record both inspiratory and expiratory concentrations of more than a single gas simultaneously but, since the anaesthesia machine used in this study had only a single $\mathrm{O}_{2}$ analyzer, we switched it from the inspiratory limb to the expiratory limb of the system to record the $\mathrm{FeO}_{2}$. The flow rate of $12 \mathrm{~L} / \mathrm{min}$ was chosen, to use the maximum calibrated $\mathrm{O}_{2}$ flow rate value available on the flow meter of our anaesthesia machine, and 10 and $8 \mathrm{~L} / \mathrm{min}$ were selected as the next alternate flow rate markings below 12 $\mathrm{L} / \mathrm{min}$. For the procedure $100 \% \mathrm{O}_{2}$ i.e. $\mathrm{FiO}_{2} \approx 1$, was used as is the standard practice during preoxygenation. The circuit was primed with $100 \% \mathrm{O}_{2}$ to reduce the time wasted in the first contact of the patient's airway with oxygen. ${ }^{7,12,13}$ The TVB technique was used for preoxygenation as it is the most standard and routinely used effective method in non emergency cases. ${ }^{12,17}$ The cut-off for adequate preoxygenation was stipulated at a $\mathrm{FeO}_{2} \geq 90 \%$ value in accordance to the standard literature. . $^{1,3,4,18,19}$

$\mathrm{SpO}_{2}$ and partial pressure of oxygen in arterial blood $\left(\mathrm{PaO}_{2}\right)$ reading as a measure of extent of alveolar denitrogenation was not used as these may be confounded by cardiac output, oxygen consumption and the characteristics of the oxygen-hemoglobin dissociation curve. ${ }^{7,25}$ Also taking $\mathrm{PaO}_{2}$ readings being an invasive procedure is cumbersome for the patients. In accordance to the studies of Sum Ping et $\mathrm{al}^{7}$ and Berry et al, ${ }^{19}$ which say that $\mathrm{SpO}_{2}$ is an inaccurate measure of preoxygenation, it was observed in our study that there was no major difference between the mean baseline $\mathrm{SpO}_{2}$ and the $\mathrm{SpO}_{2}$ at $\mathrm{FeO}_{2} \geq 90 \%$ value for all the 3 study groups.
All the high risk patient categories who have altered respiratory physiology (e.g. reduced FRC), and also those with difficult face mask seal in whom there are high chances of leak, were excluded from the study because, the results obtained in them cannot be generalized.

According to the results of our study, it was found that the time (in sec) taken by the Group 8 patients $(284.07 \pm 36.92)$ was significantly higher than the time taken by Group 10 patients $(199.87 \pm 20.71)(\mathrm{P}=0.000)$, which in turn was significantly higher than that taken by the Group 12 patients $(140.67 \pm 27.88)(\mathrm{P}=0.000)$.

In a similar study conducted by Sum Ping et al, ${ }^{7}$ the time to reach $\mathrm{FeN}_{2}$ concentration of $5 \%$ was noted by using a circle absorber system with FGF of 5 and 10 $\mathrm{L} / \mathrm{min}$ for TVB technique, once without priming the circuit and then priming the circuit with $100 \% \mathrm{O}_{2}$ at both the flow rates. Their results showed that the time taken to denitrogenate was significantly shorter with priming compared to without priming. However, when the FGF was increased the time to denitrogenate was even shorter, and priming was no longer significant. According to them using a high FGF can dilute the $\mathrm{N}_{2}$ rebreathing and leads to faster preoxygenation. Thus, the time to preoxygenate was significantly shorter with an increased flow rate of oxygen according to their study, which is in accordance to our study. Although the time achieved by them at $10 \mathrm{~L} / \mathrm{min}$ with a primed circuit was lower to that achieved in our study $(103.7 \pm 33.7$ vs. $199.87 \pm 20.71 \mathrm{sec})$, which could be due to the fact that they used a nose clip and mouth piece to preoxygenate in contrast to the face mask breathing applied in our study which is more likely to cause leaks and room air entrainment. Also the difference in the sample size (14 vs. 30 ) and the study population (US vs. Indian) can be associated with the difference in the results.

The study conducted by Russell et a ${ }^{15}$ investigated the effect of FGF on preoxygenation for a duration of 3 min, in cases of elective caesarean section. A similar technique of preoxygenation to our study was used. According to their observation, preoxygenation improved by increasing the FGF from 5 to $10 \mathrm{~L} / \mathrm{min}$ which is in agreement to our study but further increasing the flow to $15 \mathrm{~L} / \mathrm{min}$ did not show any improvement, which is contrary to our study where increasing the FGF beyond $10 \mathrm{~L} / \mathrm{min}$ reduced the time taken for preoxygenation. This could be explained by the fact that the FRC in pregnant patients is reduced compared to the non pregnant, ${ }^{1,4}$ thus probably defying the need for a higher FGF above $10 \mathrm{~L} / \mathrm{min}$. However, they were also of the opinion that by increasing the FGF, nitrogen expulsion from the circle system is enhanced therefore optimizing the preoxygenation.

One of the earliest studies done on preoxygenation, by Hamilton et $\mathrm{al}^{26}$ which was conducted on normal volunteers, studied the time taken for denitrogenation $\left(\mathrm{FeN}_{2}=5 \%\right)$ using different breathing systems. For a 
circle system preoxygenation was carried out at 1, 2, 3, 4, 5, and $10 \mathrm{~L} / \mathrm{min}$ FGFs. The time taken for denitrogenation reduced from that taken at $1 \mathrm{~L} / \mathrm{min}$ flow to that taken at $5 \mathrm{~L} / \mathrm{min}$ flow. They concluded that the rate of denitrogenation is affected by the rate of flow of gases more than by the system used but there is no clinical advantage in using flow rates $>4 \mathrm{~L} / \mathrm{min}$, which is contrary to the result of our study. The reason for this discrepancy may be attributed to the efficiency and sensitivity of the gas analyzer used, concerning the period in which their study was performed.

In a study conducted by Nimmagadda et al, ${ }^{12}$ TVB and Deep Breathing (DB) techniques of preoxygenation were studied using a similar breathing setup as used in our study on healthy volunteers. FGFs of 5, 7, and 10 $\mathrm{L} / \mathrm{min}$ were used. Similar to the Russell et al study, the duration of preoxygenation was kept constant and $\mathrm{FiO}_{2}$ and $\mathrm{FeO}_{2}$ were recorded. According to their result $\mathrm{FeO}_{2}$ at $2.5 \mathrm{~min}$ with all the FGFs was $<90 \%$, and to achieve a $\mathrm{FeO}_{2} \geq 90 \%$ a minimum 3-4 min of TVB was required. This is in agreement to our study for preoxygenation with $10 \mathrm{~L} / \mathrm{min}$ which is the only similar flow rate used here. But, increasing the FGF from 7 to $10 \mathrm{~L} / \mathrm{min}$ did not result in any significant faster increase in $\mathrm{FeO}_{2}$ in their study, which is in disagreement to our results. Although this difference can be due to the difference in the study parameters i.e. they recorded $\mathrm{FeO}_{2}$ values keeping the time for preoxygenation constant whereas in our study we recorded the time to preoxygenate keeping a fixed cut-off value of $\mathrm{FeO}_{2}$ at $90 \%$.

However, they found a significant improvement in preoxygenation using $\mathrm{DB}$ technique for more than 1 min with the increase in FGF, which was outside the domain of our study. Although the reason for this improvement with increase in FGF was again said to be the minimization of nitrogen rebreathing in the circle system for high minute ventilation breathing as in the case of DB technique and not in case of TVB technique.

So, the result of our study (the primary outcome) is in conformity with the results of a few previous studies showing that the time to achieve adequate preoxygenation i.e. $\mathrm{FeO}_{2}$ value of $\geq 90 \%$, ranges between 2 to 5 min depending on the FGF of oxygen used, with tidal volume breathing technique on a circle absorber system. This correlates with the hypothesis or the standard preoxygenation guideline of 3 to $5 \mathrm{~min}$.

Also, we observed that this time decreases with an increase in the FGF, i.e. higher flow rates lead to faster preoxygenation when an appropriate technique is applied, which is the secondary outcome of our study.

The major advantage of this study over most of the previous studies is that it considers the FGF used for preoxygenation which is an important factor for an effective preoxygenation to take place. The study was designed so, that it used the same anaesthesia machine for all the patients and a circle absorber system was implied which minimizes rebreathing. The patients were randomly assigned to one of the three groups, and all patients in whom the process of respiration can be affected by their disease process were excluded. This ensured avoidance of any chances of bias. The patients were properly counseled before the procedure to avoid any conscious effort at performing the procedure and pre procedure sedation was avoided, which ensured accurate data collection. The analysis and interpretation of the data was done in concordance with inputs by a qualified statistician.

The major limitation of our study was that the anaesthesia machine used by us could not simultaneously record the values of inspired and expired fraction of oxygen and also could not determine the concentration of other gases in the circuit which would have helped us to know the amount of rebreathing taking place.

This study can be further extended to analyze the effect of increasing the FGF with the rapid techniques of preoxygenation. Also, the efficacy and efficiency of slow and rapid techniques of preoxygenation can be compared for emergency vs. elective surgeries. The efficiency of preoxygenation by noting the DAWD can also be studied. Ideal time required for preoxygenation in different patient groups like pregnant, obese, pediatric, elderly, and patients with pulmonary disease can be studied, which will help to formulate a fixed guideline that can be followed universally.

This study concludes that a high oxygen flow rate like $12 \mathrm{~L} / \mathrm{min}$ can be used to expedite the process of preoxygenation using a circle absorber system with an adequate face mask seal, while maintaining tidal volume breathing i.e. without needing the patient to deep breath. This is particularly beneficial in emergency situations as it reduces the time to provide general anaesthesia.

\section{Conflicts of Interest: None.}

\section{References}

1. Tanoubi I, Drolet P, Donati F. Optimizing preoxygenation in adults. Can J Anaesth. 2009;56:449466.

2. Weingart SD, Levitan RM. Preoxygenation and prevention of desaturation during emergency airway management. Ann Emerg Med. 2012;59(3):165-175.

3. Bouroche G, Bourgain J. Preoxygenation and general anesthesia: a review. Minerva Anestesiol. 2015;81(8):910-920.

4. Nimmagadda U, Salem MR, Crystal GJ. Preoxygenation: Physiologic Basis, Benefits, and Potential Risks. Anesth Analg. 2017;124(2):507-517.

5. Baillard C, Depret F, Levy V. Incidence and prediction of inadequate preoxygenation before induction of anaesthesia. Ann Fr Anesth Reanim. 2014;33:e55-e58.

6. Baraka AS, Taha SK, Aouad MT, El-Khatib MF, Kawkabani N: Pre-oxygenation: Comparison of maximal breathing and tidal volume breathing techniques. Anesthesiol. 1999;91:612-616. 
7. Sum Ping SJ, Makary LF, Van Hal MD. Factors influencing oxygen store during denitrogenation in the healthy patient. J Clin Anesth. 2009;21(3):183-189. doi: 10.1016/j.jclinane.2008.07.004.

8. Groombridge CJ, Ley E, Miller M, Konig T. A prospective randomized trial of preoxygenation strategies available in the pre-hospital environment. Anaesth. 2017;72(5):580-584.

9. Mort TC. The incidence and risk factors for cardiac arrest during emergency tracheal intubation: a justification for incorporating the ASA guidelines in the remote location. J Clin Anesth. 2004;16:508-516.

10. Davis DP, Lemieux J, Serra J, Koenig W, Aguilar SA. Preoxygenation reduces desaturation events and improves intubation success. Air Med J. 2015;34(2):82-85.

11. Benumof JL. Preoxygenation: best method for both efficacy and efficiency. Anesthesiol. 1999;91(3):603-605.

12. Nimmagadda U, Chiravuri SD, Salem MR. Preoxygenation with tidal volume and deep breathing techniques: the impact of duration of breathing and fresh gas flow. Anesth Analg. 2001;92:1337-1341.

13. Kundra P, Stephen S, Vinayagam S. Techniques of preoxygenation in patients with ineffective face mask seal. Indian $J$ Anaesth. 2013;57(2):175-179.

14. Nimmagadda U, Salem MR, Joseph NJ. Efficacy of preoxygenation with tidal volume breathing: comparison of breathing systems. Anesthesiology 2000;93:694-8.

15. Russell E, Wrench I, Feast M, Mohammed F. Preoxygenation in pregnancy: the effect of fresh gas flow rates within a circle breathing system. Anaesth. 2008;63(8):833-836.

16. Berthoud MC, Peacock JE, Reilly CS. Effectiveness of preoxygenation in morbidly obese patients. $\mathrm{Br} J$ Anaesth. 1991;67(4):464-466.

17. Kang H, Park HJ, Baek SK, Choi J, Park SJ. Effects of preoxygenation with the three minutes tidal volume breathing technique in the elderly. Korean J Anesth. 2010;58:369-373.

18. Bhatia PK, Bhandari SC, Tulsiani KL, Kumar Y. Endtidal oxygraphy and safe duration in young adults and elderly patients. Anaesth. 1997;52:175-188.
19. Berry CB, Myles PS. Preoxygenation in healthy volunteers: a graph of oxygen "washin" using end-tidal oxygraphy. Br J Anaesth. 1994;72:116-118.

20. McGowan P, Skinner A. Preoxygenation-the importance of a good face mask seal. Br J Anaesth. 75:777-778.

21. Hagberg CA, Artime CA. In: Airway Management in the Adult. RD Miller et al. Miller's Anesthesia, 8th ed., pp.16471683. Philadelphia: Saunders.

22. American Society of Anesthesiologists Task Force on Management of the Difficult Airway. Practice guidelines for the management of the difficult airway. Anesthesiol. 2003;98:1269-1277.

23. Frerk C, Mitchell VS, McNarry AF, et al. Difficult airway society 2015 guidelines for management of unanticipated difficult intubation in adults. Br J Anaesth. 2015;115:827-848.

24. Myatra SN, Shah A, Kundra P, Patwa A, Ramkumar V, Divatia JV, et al. All India Difficult Airway Association 2016 guidelines for the management of unanticipated difficult tracheal intubation in adults. Indian J Anaesth. 2016;60:885-898.

25. Gold MI, Duarte I, Muravchick S. Arterial oxygenation in conscious patients after 5 minutes and after 30 seconds of oxygen breathing. Anesth Analg. 1981;60:313-315

26. Hamilton WK, Eastwood DW. A study of denitrogenation with some inhalation anesthetic systems. Anesthesiol.1955;16:861-867.

How to cite this article: Chaudhari M S, Bansal $\mathrm{P}$, Khara B. Increasing fresh gas flows of oxygen in a circle absorber system for preoxygenation. Is it really efficacious? Indian J Clin Anaesth. 2018;5(4):609-613. 